\title{
El principio de orden público y el régimen tuitivo consumidor en el derecho argentino
}

The Public Order Principle and Consumer
Rights Protection in the Argentine Law

Carlos Eduardo Tambussi*

http://dx.doi.org/10.21503/lex.v14i18.1236

* Abogado, Universidad de Buenos Aires (1991). Procurador Adjunto de Asuntos Patrimoniales y Fiscales del Gobierno de la Ciudad Autónoma de Buenos Aires (2010-2012). Secretario del Juzgado Nro. 18, Secretaría 35 del Fuero Contencioso Administrativo y Tributario de la CABA (2013-actualidad). Profesor adjunto regular de la Universidad de Buenos Aires, Facultad de Derecho. Cátedra: Dr. Agustín Gordillo. Asignatura: Derechos Humanos y Garantías. Profesor a cargo del curso Protección Constitucional de Consumidores y Usuarios del Ciclo Profesional Orientado en la Facultad de Derecho (UBA). Docente en seminarios y cursos de posgrado sobre Derechos de Consumidores y Usuarios. Presidente de la Comisión de Derecho del Consumidor de la Asociación de Abogados de Buenos Aires. Autor de libros y varios artículos de la especialidad. E-mail: cetambu@uolsinectis.com.ar

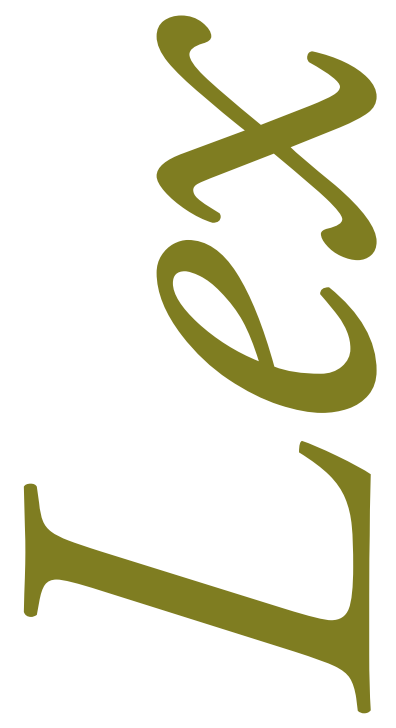




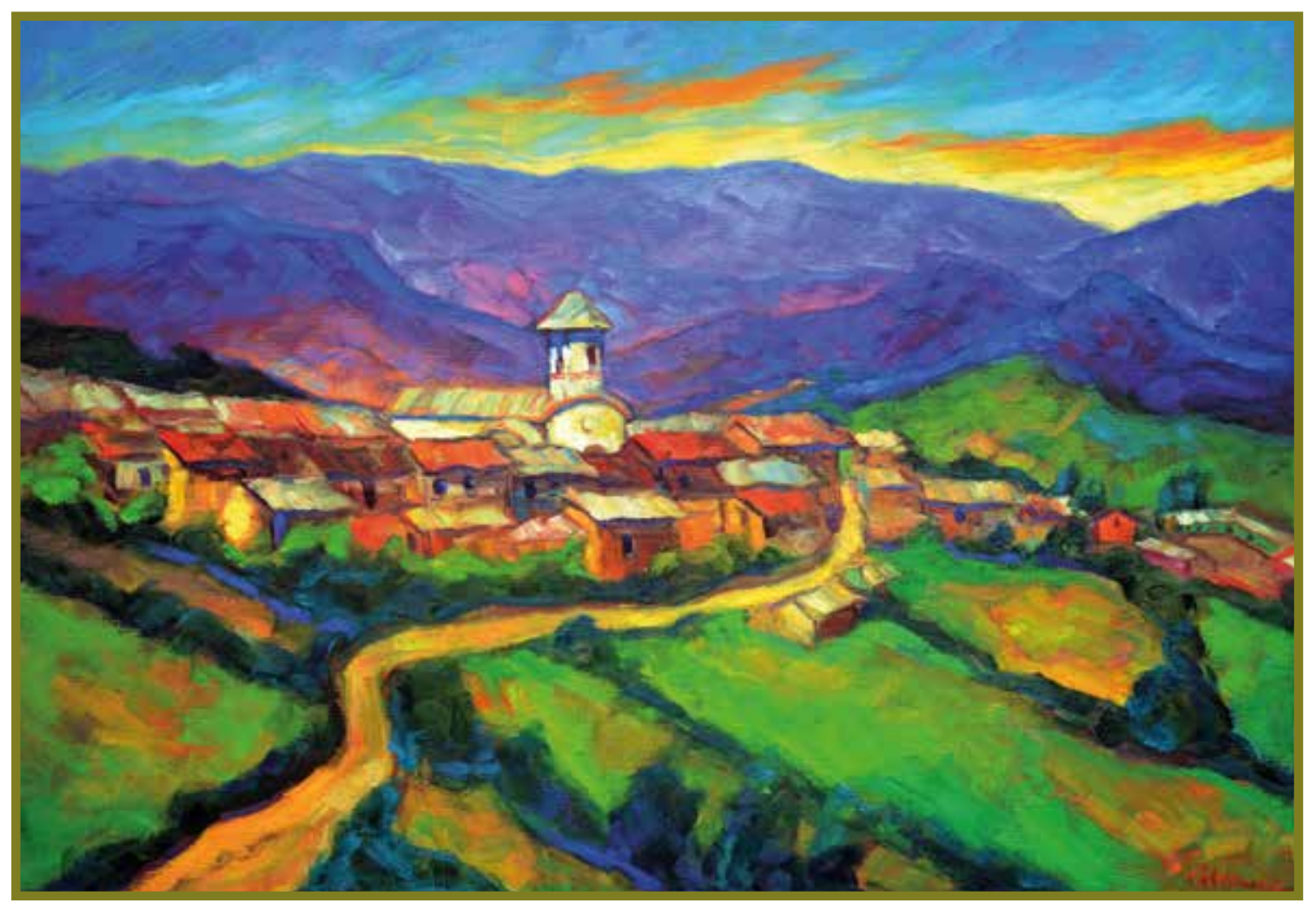

San Gregorio querido. Óleo sobre lienzo $(81 \mathrm{~cm}$ x $116 \mathrm{~cm})$. Ever Arrascue. 


\section{RESUMEN}

El principio de orden público es una máxima fundamental para la vigencia del derecho de usuarios y consumidores, concebido como derecho protectorio o tuitivo del más débil en la llamada relación de consumo. Implica regulación estatal en las relaciones individuales estableciendo estándares inderogables e irrenunciables con base en el principio protectorio y con un propósito equilibrador. Este principio es el eje de la Ley 24240 o Estatuto Especial del Consumidor en la República Argentina, que ha sido reforzado con la sanción del Código Civil y Comercial vigente desde agosto del 2015, conviviendo bajo el régimen de la norma más favorable.

Palabras clave: derechos del consumidor, protección, principios, orden público, autonomía de la voluntad, intervención estatal, mínimos inderogables, irrenunciabilidad, aplicación por los jueces, implicancias prácticas.

\section{ABSTRACT}

The public order principle is a core idea for the validity of consumer rights law conceived as the rules protecting the weaker party in the consumer-provider relationship. It involves state regulation of individual relationships establishing irrevocable and inalienable standards based on the protective principle aimed at setting a balance between consumers and providers. This principle is one of the pillars of the Act $\mathrm{N}^{\circ} 24240$ (Consumer Protection Act) from the Argentine Republic, reinforced by the Civil and Commercial Code enactment in August 2015, involving the application, in case of doubt, of the most favorable rule for consumers.

Key words: consumer rights, protection, principles, public order, free will, state intervention, minimum standards, inalienable rights, application by judges, practical implications. 


\section{RÉGIMEN TUITIVO CONSUMIDOR. DERECHO PROTECTORIO. PRINCIPIOS}

Los principios se comportan como "máximas" o pautas extraídas de los fines de una rama del derecho que son tenidas como la "esencia" de esa esfera del saber jurídico y se encuentran estrechamente ligados a los "derechos" que se extraen de las normas.

Son directivas básicas positivizadas que amparan valores políticos que se juridizan al normarse, y que constituyen las pautas interpretativas del tópico que se regula y son propios de él, por lo que contribuyen a su autonomía como disciplina.

En el caso del derecho de usuarios y consumidores, se trata de principios protectorios, ideados a los fines de disminuir la debilidad en que se encuentra el usuario frente al proveedor.

En nuestro derecho, el "consumo" constituye un principio informador del ordenamiento, mediante una concepción omnicomprensiva y multidisciplinaria, que ha cambiado el enfoque del derecho, ${ }^{1}$ obligado a ser comprendido en forma diferente cuando se trata de una relación de consumo, dada la desigualdad negocial existente entre los protagonistas. Por esa razón, nos referiremos al "régimen tuitivo consumidor".

La concepción jurídica del derecho del consumidor como tuitivo importa el abandono del principio de la igualdad formal ante la ley, para proteger a la que es la parte más débil, que se encuentra inerme frente a las empresas y a los profesionales con los que se relaciona. El derecho protectorio consiste en contemplar, entonces, esa imposibilidad que tenemos los consumidores de juzgar por nosotros mismos calidades, precios, materiales de elaboración, condiciones y modalidades de contratación.

Los principios deben ser tenidos en cuenta a la hora de la aplicación de las normas a situaciones específicas y son de necesario seguimiento por el intérprete, sirviendo también

1 Véase Marcelo Taboada, "En torno a La Ley de Defensa del Consumidor y a las observaciones formuladas por el Poder Ejecutivo”, La Ley (1994-A): 766. Cita online: AR/DOC/20155/2001. 
para superar la existencia de vacíos o ambigüedades legales. Comprenden el principio in dubio pro consumidor, la aplicación de la norma más favorable en caso de duda, el orden público consumidor o principio de irrenunciabilidad y la operatividad de las normas legales y constitucionales. Se incluyen además los principios de buena fe, confianza, transparencia, primacía de la realidad y el principio de sustentabilidad. ${ }^{2}$

A su vez, en su condición de derechos humanos, los de usuarios y consumidores se encuentran delimitados por el principio de no regresividad y por la irrestricta vigencia del principio de no discriminación.

En el mundo del consumo, hizo crisis incluso la definición misma de contrato como acuerdo de voluntades que utilizaba el Código Civil derogado, teniendo en cuenta que la desigualdad en la posición de las partes ante el acuerdo acota a la libertad; la imposibilidad de prescindir del consumo limita el discernimiento y condiciona la libertad, y se traduce en menoscabo y perjuicio para una de las partes de la relación, que no puede negociar el contenido de la prestación, no teniendo otra alternativa más que aceptar lo impuesto o prescindir del bien o servicio buscado (lo cual torna dramático el dilema en caso de que este le resulte imprescindible). El derecho del consumo busca acercar la materia contractual a la realidad, mediante un imperativo de solidaridad que cuestiona el dogma de la autonomía de la voluntad, dando primacía al valor del equilibrio entre las partes, mediante los principios de proporcionalidad, la coherencia, cooperación y buena fe.

Además, y adentrándonos en el principio de orden público, el régimen tuitivo consumidor implica superar el estigma por cual la regulación estatal a través de la fijación de contenidos inalterables por sobre la autonomía de la voluntad constituye un sacrilegio a la inconmovible libertad contractual y asumir el imperativo ético del valor solidaridad social.

En síntesis, que el derecho de usuarios y consumidores sea un derecho protectorio importa el abandono del principio de la igualdad formal ante la ley, propio del esquema clásico del derecho civil y comercial, para proteger a la parte más débil, que se encuentra inerme frente a las empresas y a los profesionales con los que se relaciona. La situación de campo caracteriza la posición del consumidor frente a la relación de consumo como la parte más vulnerable de la misma (situación de débil jurídico). A tal desigualdad natural se propicia corregirla mediante desigualdades jurídicas, inclinando el derecho para el lado contrario de la realidad, lo cual converge en la formulación del derecho de consumo como derecho tuitivo.

2 Véase Sergio Sebastián Barocelli, "Principios y ámbito de aplicación del derecho del consumidor en el nuevo Código Civil y Comercial, Derecho Comercial, del Consumidor y de la Empresa (febrero 2015): 63. 


\section{CONCEPTO DE ORDEN PÚBLICO}

Se entiende por orden público a un conjunto de principios a los cuales se vincula la subsistencia de la organización social establecida. ${ }^{3}$ Implica considerar el interés general o comunitario sobre el particular y hace a los valores permanentes del Estado. ${ }^{4}$

Otra definición nos lo describe como el conjunto de condiciones fundamentales de vida social instituida en una comunidad jurídica, las cuales, por afectar centralmente la organización de estos, no pueden ser alteradas por la voluntad de los individuos ni, en su caso, por la aplicación de normas extranjeras. ${ }^{5}$

La Corte Suprema de Justicia Nacional de la Argentina precisó que el legislador, al disponer que es de orden público, ha definido a la ley como contenedora de un conjunto de principios de orden superior estrechamente vinculados a la existencia y conservación de la organización social establecida y limitadora de la autonomía de la voluntad. ${ }^{6}$

\section{SIGNIFICADO DEL ORDEN PÚBLICO}

Se trata de un límite a la libertad contractual, donde se pondera la utilidad social por encima de la libertad sin límites.

Uno de los límites lo constituyen las normas imperativas, que tienen un rango superior sobre las convenciones particulares, lo que se traduce en su carácter coactivo, impidiendo su apartamiento. Es, en suma, intervención estatal protectoria, mediante el establecimiento de un estándar básico, emergente de la ley, que atiende a razones políticas, sociales, económicas, morales y humanas relacionadas con la materia que se regula, y que hacen que se considere a esos valores como necesitados de una regulación de esas características. Esas categorías axiológicas varían con el tiempo y dependen de la consideración política que de ellas se tenga para que se plasmen de una manera o de otra, según épocas. Y también, para que se mantengan o varíen, dependen del juego de mayorías y preponderancias.

Pero en el caso de los principios emanados de normas constitucionales y consagrados en preceptos legislativos que derivan de ellas, sus criterios tienden a ser más permanentes y estables frente a los vaivenes ideológicos. Justamente se trata de plasmar las llamadas "políticas de estado", que sobrevivan a las variables ocasionales de regímenes políticos y que necesiten

3 Jorge Joaquín Llambías, Tratado de derecho civil. Parte general, tomo I (Buenos Aires: Lexis Nexis, 2007), 145.

4 Cámara Nacional de Apelaciones en lo Comercial, sala A, 17/05/2000, "Western Universal Management Inc. c Nosiglia, Enrique", La Ley (2001-A): 642.

5 Véase Julio César Rivera, Instituciones de derecho civil - Parte general, tomo I (Buenos Aires: Ed. Abeledo Perrot, 1997), 99 y ss.

6 Corte Suprema de Justicia Nacional P. 344. XXIV, "Partido Justicialista s/acción de amparo", 28/09/1993, T. 316, P. 2117 (Voto del Dr. Carlos S. Fayt). 
para su modificación la reunión de voluntades también políticas, pero más agravadas en cuanto a número y procedimiento, como sería el caso de una reforma constitucional.

Se vigila, entonces, que lo convenido entre partes sea conforme con valores considerados fundamentales, en respeto de un umbral de ética y dignidad y de la función social del derecho, estableciendo un "minimum inderogable".

\section{EL ORDEN PÚBLICO EN EL RÉGIMEN TUITIVO CONSUMIDOR}

\section{La convivencia entre el estatuto especial y el nuevo Código argentino}

El art. 65 de la ley 24240 de Defensa del Consumidor establece que "la presente ley es de orden público, rige en todo el territorio nacional".

Esa ley o estatuto especial del consumidor coexiste con el reciente Código Civil y Comercial (ley 26994, vigente desde agosto de 2015). ${ }^{7}$

Los enunciados del proyecto explicaron que se propuso incluir en el Código Unificado una serie de principios generales de protección del consumidor que actúan como una "protección mínima”, sin que ello signifique obstáculo para que una ley especial establezca condiciones superiores, y a la inversa, ninguna podrá afectar esos mínimos de protección o "núcleo duro de tutela”. En este punto marcamos nuestra discrepancia, considerando núcleo al estatuto especial.

En el campo de la interpretación, se argumenta establecer un "diálogo de fuentes", de manera que "el Código recupera una centralidad para iluminar a las demás fuentes. El intérprete de una ley especial recurrirá al Código para el lenguaje común de lo no regulado en la ley especial y, además, para determinar los pisos mínimos de tutela conforme con el principio de interpretación más favorable al consumidor ${ }^{8}$ En esta parte de la argumentación, se atenúa la aparente prelación del Código sobre la ley especial.

De esa manera se plasmó la pretensión de dar una base más “perenne”, a través del Código, con base en que, si bien puede ser modificado, "es mucho más difícil hacerlo que con relación a cualquier ley especial", con arraigo en el fenómeno de la "constitucionalización del derecho privado"?

7 Nota del autor. Otros países, como Italia y España, mantienen en forma separada la regulación de sus códigos y la especial de consumidores y usuarios (Decreto Legislativo 206 del 6 de septiembre de 2005 y Real Decreto Legislativo 1/2007 del 16 de noviembre de 2007). Por otro lado, Alemania incorporó en 2002 alunas normas de consumidor a su Código, al igual que los casos de Quebec (1991) y Holanda (1992).

8 Conforme lo señalaron los fundamentos del proyecto de reforma.

9 Derechos que, por su importancia, tienen un especial interés para la sociedad, de origen y sustento moral, ético, y como hemos dicho supra, económico, en este caso con raigambre constitucional y en tal carácter se incluyen los derechos del consumidor como parte de los llamados "derechos civiles constitucionalizados". Véase Ricardo Luis Lorenzetti, Consumidores (Buenos Aires: Ed. Rubinzal- Culzoni, 2009), 45. 
El nuevo Código Unificado carece de una norma similar a la del artículo 65, por lo que, salvo en lo que respecta a los principios derivados de los tratados internacionales de derechos humanos, su carácter de normas indisponibles o no debe interpretarse en cada caso, y han surgido ya debates al respecto.

Al tratar los contratos de consumo, el Código replica algunos institutos ya consignados en la LDC, pero también recepta principios y criterios que resultan altamente beneficiosos para los sujetos protegidos, mediante la incorporación de regulaciones generales necesarias para el ejercicio de sus derechos, e introduce en el cuerpo legislativo conceptos tendientes a reafirmar el equilibrio prestacional, y recibe, al fin, particularidades de la contratación moderna, en especial la electrónica, hasta ahora ausente de regulación.

A la vez, la incorporación codificada de normas protectorias contribuye a la jerarquización de la disciplina del derecho del consumo (muchas veces relegada) en la medida que se interprete que la nueva modalidad viene a enriquecer el estatuto y que por la vigencia de los principios protectorios debe interpretarse y aplicarse siempre del modo más favorable al consumidor, constituyendo una determinación de niveles mínimos de protección "más difíciles de modificar" ${ }^{10}$ que la ley 24240 , pero que de ninguna manera la desvirtúa o reduce en sus alcances, ni afecta su carácter.

El Código recepta muchos criterios ya contenidos en la ley 24240, a la cual no deroga, salvo algunos artículos que se modifican, con lo cual existirán aspectos que tendrán aplicación de los dos ordenamientos, y en muchos casos la superposición de protecciones puede traer algunos problemas de interpretación y de prelación normativa que esperamos la jurisprudencia y doctrina contribuyan a esclarecer y precisar, manteniendo los criterios que se venían desarrollando antes de la sanción de la Ley 26994 de unificación, en especial el de la aplicación de la norma o la interpretación más favorable y la intangibilidad de los institutos de la Ley 24240.

No surge con claridad del articulado del Código si la Ley de Defensa del Consumidor, que es ley especial y reglamentaria de los Art. 42 y $43 \mathrm{CN}$, será prevalente, más allá de que algunas de sus disposiciones sean reiteradas o levemente diferenciadas en el Código Unificado, para tener en claro que siendo una ley de orden público en su integralidad (Art. 65 LDC) mantendrá su vigencia por sobre las disposiciones de la ley común (Código Civil y Comercial).

No obstante, las normas del nuevo Código claramente establecen que los límites de la libertad contractual son el orden público, la moral y las buenas costumbres (art. 958), y que los jueces pueden modificar de oficio las convenciones particulares cuando este valor se

10 Nota del autor. Sobre esta afirmación de los fundamentos de la reforma entendemos que refomar un Código no es más difícil, sino tan solo menos frecuente. 
encuentre afectado de modo manifiesto (art. 960). A su vez, determina que las convenciones particulares no pueden dejar sin efecto las leyes en cuya observancia esté interesado el orden público (art. 12). Y existen referencias al orden público en los artículos 7, 144, 151, 279, 386, $515,1014,1644,2477,2600,2637,2651$ y $2634 . .^{11}$

Incluso por aplicación del orden público y el principio de norma más favorable, las normas más beneficiosas para el consumidor son de aplicación inmediata a las relaciones jurídicas prexistentes, en términos del artículo $7^{\circ}$ del nuevo cuerpo codificado:

Artículo $7^{\circ}$.- Eficacia temporal. A partir de su entrada en vigencia, las leyes se aplican a las consecuencias de las relaciones y situaciones jurídicas existentes. Las leyes no tienen efecto retroactivo, sean o no de orden público, excepto disposición en contrario. La retroactividad establecida por la ley no puede afectar derechos amparados por garantías constitucionales. Las nuevas leyes supletorias no son aplicables a los contratos en curso de ejecución, con excepción de las normas más favorables al consumidor en las relaciones de consumo (resaltado nuestro).

\section{Esencia del orden público consumidor. Alcances}

Tratándose en el caso del derecho de consumidores y usuarios de un régimen tuitivo o protectorio, el carácter de orden público de sus normas es fundamental y determinante para su efectividad, y provoca la nulidad de los actos que se hubiesen celebrado su contravención. ${ }^{12}$ Ello así por cuanto sus principios no son susceptibles de ser transados, ni modificados, ni disminuidos, aun cuando medie la voluntad del usuario.

Por esa razón, el orden público consumidor es una regla que admite muy pocas excepciones, al derivar de un valor constitucional de protección al débil o al vulnerable, y en esa inteligencia el legislador argentino le atribuyó a la Ley 24240 carácter de indisponible en su totalidad. La defensa del consumidor se encuentra así determinada como finalidad de la ley, y la caracteriza como la instauración de un régimen tuitivo o protectorio. Se trata de una toma de posición, una declaración de objetivos, que privilegia la situación de consumidores y usuarios con un propósito equilibrante y nivelador. La ley está de parte del débil, para ponerlo en igualdad de posibilidades y compensarle sus debilidades estructurales frente al proveedor.

El contenido imperativo de las normas de la Ley de Defensa del Consumidor se impone sobre la autonomía de la voluntad. Orden público es imperium del estado, ${ }^{13}$ que mediante

11 Véase Roberto Enrique Luqui, "Reflexiones sobre el concepto de orden público”, La Ley on line. Cita AR/DOC/283/2016.

12 Véase Jorge Mosset Iturraspe, "El orden público y la tutela del consumidor o usuario", Revista UNAM, N 90, año V (enero-diciembre 2008): 223-233.

13 "No puede razonablemente admitirse que resulten suficientes para el mundo negocial contemporáneo las rígidas formas de contratación basadas en la presencia de la autonomía de la voluntad como principio soberano y excluyente. Esto ya no se discute". Ver Mónica Puga, "El derecho y el orden público, con particular referencia al derecho del Consumo", El Dia. Cita: elDial.com - DC189D. 
su poder normativo, y con base en la trascendencia social e importancia de lo que se regula, impone contenidos considerados principios fundamentales o pautas que necesariamente deben seguir las convenciones particulares ${ }^{14}$ y que la sociedad y sus intereses generales han considerado necesario establecer a partir de la ley con contenidos inmodificables, quedando fuera solo las excepciones que expresamente adjudiquen carácter de disponibles a algunos aspectos normativos, siempre con resguardo del principio protectorio.

De ahí que las previsiones de la Ley de Defensa del Consumidor importen un piso mínimo de protección que puede ser innovado en más por los acuerdos particulares, y a la vez el orden público como criterio converge en que toda renuncia o disminución del marco de protección repugna a este carácter y es por ende inoponible al consumidor y viciadas de nulidad.

La protección carecería de todo fundamento si el proveedor pudiese aprovecharse de la inferioridad del consumidor y su estado de necesidad, imponiéndole renuncias a derechos a cambio de satisfacerla. La norma entera quedaría privada de efectos prácticos de no revestir esta característica.

Por ello, la Ley de Defensa del Consumidor es aplicable independientemente de que las partes hayan o no invocado dicho sistema legal, pues corresponde al juez determinar el derecho aplicable a los hechos planteados por los litigantes, más allá de la calificación que estos les hayan asignado ${ }^{15}$ e incluso su aplicación de oficio, lo cual no es una facultad sino un deber de los magistrados, en cumplimiento con la prescripción del art. 42 de la Constitución Nacional Argentina, que impone a las autoridades públicas el deber de proveer a la defensa de los derechos de los consumidores. ${ }^{16}$

La norma constitucional del artículo 42 le otorga a la Ley 24240 un rango superior al legislativo, incluyéndola dentro de los "Nuevos Derechos y Garantías" que pasaron a ampliar

14 El orden público-institución constituye el instrumento de que se vale el ordenamiento jurídico para garantizar, mediante la limitación de la autonomía de la voluntad, la vigencia irrestricta de los intereses generales de la sociedad (orden público-objeto) de modo que siempre prevalezcan sobre los intereses particulares. Y para alcanzar el objetivo de proteger y preservar tales intereses generales, el orden público-institución produce efectos jurídicos muy importantes, predeterminados ya por el sistema, que consisten en atribuir imperatividad a las normas, declarar irrenunciables los derechos adquiridos, posibilitar que en ciertos casos se apliquen las leyes de oficio e invalidar los actos violatorios del orden público, además de otras sanciones.

15 Cámara Nacional de Apelaciones en lo Civil, sala A, "Petrillo, José Luis c. Repetto, Oscar Osvaldo y otros s/daños y perjuicios”, 11/04/2013, Responsabilidad Civil y Seguros, IX (2013): 130.

16 Constitución argentina. Artículo 42: Los consumidores y usuarios de bienes y servicios tienen derecho, en la relación de consumo, a la protección de su salud, seguridad e intereses económicos; a una información adecuada y veraz; a la libertad de elección, y a condiciones de trato equitativo y digno. Las autoridades proveerán a la protección de esos derechos, a la educación para el consumo, a la defensa de la competencia contra toda forma de distorsión de los mercados, al control de los monopolios naturales y legales, al de la calidad y eficiencia de los servicios públicos, y a la constitución de asociaciones de consumidores y de usuarios. La legislación establecerá procedimientos eficaces para la prevención y solución de conflictos, y los marcos regulatorios de los servicios públicos de competencia nacional, previendo la necesaria participación de las asociaciones de consumidores y usuarios y de las provincias interesadas, en los organismos de control. 
el catálogo de la parte dogmática. ${ }^{17}$ A su vez, ha creado un sistema autónomo, donde la especialidad está dada por la existencia de una relación de consumo, y que se proyecta sobre todo el orden jurídico, y si bien se integra y no deroga aquellas previsiones que regula el Código Civil y Comercial sobre esta materia, en casos de colisión entre estas normativas debe primar la Constitución Nacional, que es la fuente principal de estos derechos, y la LDC 24240, reglamentaria de los derechos reconocidos en la norma constitucional. La Ley de Defensa del Consumidor se ha erigido en ley especial respecto de las propias relaciones de consumo, y por ende sus principios se deben privilegiar por encima de los ordenamientos civiles y mercantiles. ${ }^{18}$

Ha señalado la jurisprudencia que "la noción de orden público viene a consolidar derechos que, por su importancia, tienen un especial interés para la sociedad, de origen y sustento moral y ético y — como hemos dicho supra - económico, en este caso con raigambre constitucional y en tal carácter se incluyen a los derechos del consumidor como parte de los llamados derechos civiles constitucionalizados" ${ }^{19}$

Del mismo modo, el orden público no impide que los ordenamientos provinciales o locales relativos a consumidor puedan innovar en términos de mayor protección, en la idea de que una protección común, mediante estándares básicos y suficientes proporcionados por la ley nacional, sea uniforme en todas las jurisdicciones. Correlativamente, las legislaciones locales deberán respetar el mínimum de protección impuesto por el ordenamiento sustantivo.

La irrenunciabilidad de los derechos de los consumidores y usuarios no se limita a los derechos emergentes de la Ley 24240, "sino a todo derecho a favor del consumidor o usuario que surja de cualquier ley nacional o provincial o disposiciones municipales, en razón de lo dispuesto por el Artículo $3^{\circ}$, según el cual el derecho de los consumidores y usuarios se integra con las disposiciones de la Ley 24240, con las normas generales y especiales aplicables a las relaciones con los proveedores de bienes y servicios encuadrables en los arts. $1^{\circ}$ y $2^{\circ} \ldots . .^{20} \mathrm{El}$ orden público, además, tiene sustento constitucional en el carácter de derechos esenciales de los incluidos en el artículo 42. Y es también un orden público económico, como reaseguro de la economía de mercado y garantía para prevenir inequidades. ${ }^{21}$

17 Véase Marcelo Alberto López Alfonsín, Protección constitucional de consumidores y usuarios (Buenos Aires: Ed. Estudio, 2000), 21.

18 Del voto mayoritario en Cámara Nacional de Apelaciones en lo Civil, "Sáez González Julia del Carmen c/ Astrada Armando Valentín y otros s/ daños y perjuicios (acc. trán. c/ les. o muerte)”, 12/3/2012, Microjuris. Cita: MJ-JU-M70925-AR/MJJ70925/MJJ70925.

19 Véase Ricardo Luis Lorenzetti, Consumidores..., 45.

20 Véase Juan M. Farina, Defensa del consumidor y del usuario (Buenos Aires: Ed. Astrea, 2008), 655.

21 Cámara Nacional de Apelaciones en lo Comercial. Sala B, 23-2-99, "Banco de Galicia c. L.H., P.M. y otros", La Ley (1999 E): 717. 
Ha sostenido la jurisprudencia que "la condición de orden público de los derechos de usuarios y consumidores, que viene a fijar directrices realistas para el mercado, impone a los jueces una interpretación amplia, extensiva y sistemática del dispositivo legal". ${ }^{22}$

\section{Las "funciones" del orden público}

Lorenzetti enuncia las cuatro funciones del orden público ${ }^{23}$ para el derecho de usuarios y consumidores:

a. Función de garantía del consentimiento pleno y de igualdad de oportunidades, en razón de la situación de desigualdad del consumidor, regulando en protección del más débil y teniendo como norte de la intervención de la ley el suprimir las distancias económico-sociales.

b. Función de coordinación, garantizando la licitud de lo pactado por las partes, en el marco del respeto a la persona en su consideración general, a la moral y a las buenas costumbres.

c. Función de dirección, por el interés del Estado (dada su importancia para la sociedad y el mercado) en organizar con base a la justicia distributiva esta área de negocios, dados los efectos sociales del contrato, brindando su tutela con medidas judiciales y administrativas que aplican el derecho protectorio de fondo. Su manifestación más profunda es la que se traduce en la intervención obligatoria del Ministerio Público Fiscal en los procesos de consumo.

d. Función de protección, por la que el orden público tiende a resguardar a una de las partes contratantes considerada la más débil y a mantener el equilibrio interno del contrato haciendo a la justicia del contrato o mejor dicho a la justicia conmutativa. Es intervención del Estado en la economía con esa finalidad.

\section{ALGUNOS EJEMPLOS DE APLICACIONES PRÁCTICAS}

\section{Temas de fondo}

\section{A. En el contenido de documentos}

Si bien es cierto que en materia contractual rige el principio de la libertad de formas, conforme a lo previsto por el Código Civil y Comercial, la Ley de Defensa del Consumidor, cuyo carácter de orden público fue establecido en su Art. 65, establece los requisitos mínimos que debe contener el documento de venta en donde se instrumenta la relación de consumo (Art. 10, Ley 24240), el cual debe ser extendido en tantos ejemplares como partes contratantes

22 Cámara de Apelaciones Contencioso, Administrativo y Tributario. Causa Nro.: 2538-0. Autos: BBVA Banco Francés S.A. c/ GCBA s/ Otras causas con tramite directo ante la Cámara de Apelaciones Sala II. Del voto de Dr. Eduardo A. Russo con adhesión de Dr. Esteban Centanaro y Dra. Nélida M. Daniele. 09-03-2010. Sentencia Nro. 12, inédito.

23 Véase Ricardo Luis Lorenzetti, Consumidores..., 25. 
haya a los fines de que ambas partes posean una constancia del contrato celebrado y sea este utilizado por ellas para exigir el cumplimiento de las obligaciones contraídas, como así también ejercer los derechos que del contrato deriven. La redacción debe ser realizada en idioma nacional para que sea comprensible por las partes, evitando reenvíos que puedan causar confusión, especialmente en aquellos contratos donde una de las partes unilateralmente establece las condiciones contractuales en donde el consumidor solo se limita a adherir a ellas.

\section{B. En el crédito al consumo}

El artículo 36 in fine de la Ley de Defensa del Consumidor, reformado en 2008, con el que comienza el capítulo VIII, "De las operaciones de venta de créditos", dice expresamente: "Será competente para entender en el conocimiento de los litigios relativos a contratos regulados por el presente artículo, siendo nulo cualquier pacto en contrario, el tribunal correspondiente al domicilio real del consumidor".

Tengamos presente que aquel que contrae un crédito se constituye en consumidor de los productos de las entidades financieras, y por ende es sujeto de protección conforme el artículo 42 de la Constitución y la Ley 24240.

Esta nueva mención autoriza a los consumidores a interponer excepción de incompetencia a los proveedores que demanden en un domicilio diferente del real del consumidor, aunque hayan pactado lo contrario, ${ }^{24}$ atento el carácter de orden público de la ley y su imposibilidad de alteración por la voluntad de las partes, procediendo lisa y llanamente su nulidad.

Y así lo han receptado los precedentes:

Es competente el juez del domicilio del deudor para entender en la ejecución de un título librado por un consumidor final en una operación de crédito, pues el vínculo establecido entre las partes aparece comprendido en las previsiones de la Ley 24240, la cual debe prevalecer sobre el Decreto Ley 5965/63 por ser de orden público. ${ }^{25}$

Al calificarse a sí misma la Ley 24240 como de orden público y otorgar al consumidor un régimen especial derivado de su condición de tal en relación con el empresario o productor de bienes o servicios, el Art. 36 es aplicable de modo imperativo en todos los casos -incluso en los juicios ejecutivos - pues sus efectos se extienden al ámbito de la legislación sustancial y procesal, de manera que el acotado marco del juicio ejecutivo no podría conspirar para eludir la protección legal. ${ }^{26}$

24 Véase Carlos A. Molina Sandoval, "Reformas sustanciales", Suplemento La Ley, "Reforma de La Ley de Defensa del Consumidor”, La Ley (2008): 105.

25 Juzgado Nacional de Primera Instancia en lo Comercial Nro. 16, 30/8/2010, "Cooperativa Palamates Ltda. C. Cabral Roberto", La Ley on line. Cita: AR/JUR/45567/2110. En igual sentido: Cámara Nacional de Apelaciones en lo Comercial, Sala F, "Banco Supervielle S.A. c. Chicui Héctor", 27/4/2010, La Ley on line. Cita: AR/JUR/22408/2010.

26 Cámara Nacional de Apelaciones en lo Comercial, sala F, 19/02/2015, "Banco de Galicia y Buenos Aires S.A. c. Dayan, Gonzalo s/ ejecutivo", La Ley on line. Cita: AR/JUR/604/2015. 


\section{En la integración normativa}

La Ley 24240 ha establecido como regla obligatoria de interpretación que en caso de duda sobre la aplicación de normas o dentro del contexto de una norma en sí, se estará siempre a la interpretación más favorable y menos gravosa para el consumidor, recurriendo, en pos de tutelar a los consumidores y usuarios en sus relaciones contractuales, a una moderna aplicación de la regla del favor debitoris. Vale decir que para interpretar las obligaciones de los usuarios debe echarse mano a dicho principio entendido como "favor al débil", criterio orientador insoslayable para interpretar la ley, atento el carácter de orden público que ostenta la misma (artículo 65, Ley 24240).

La Ley de Defensa del Consumidor aplica este principio con referencia a:

a. La propia Ley de Defensa del Consumidor: "En caso de duda sobre la interpretación de los principios que establece esta ley prevalecerá la más favorable al consumidor" (artículo 30);

b. Legislación referida a servicios públicos domiciliarios: "En caso de duda sobre la normativa aplicable, resultará la más favorable para el consumidor" (Ley de Defensa del Consumidor, artículo 25\%).

Por su parte, el Código lo recepta:

a. En los fundamentos del proyecto, donde se expresa que en el campo de la interpretación se busca establecer un "diálogo de fuentes", de manera que "el Código recupera una centralidad para iluminar a las demás fuentes. El intérprete de una ley especial recurrirá al Código para el lenguaje común de lo no regulado en la ley especial y, además, para determinar los pisos mínimos de tutela conforme con el principio de interpretación más favorable al consumidor". ${ }^{27}$

b. En el Art. 1094: "Las normas que regulan las relaciones de consumo deben ser aplicadas e interpretadas conforme con el principio de protección del consumidor y el de acceso al consumo sustentable. En caso de duda sobre la interpretación de este Código o las leyes especiales, prevalece la más favorable al consumidor".

Por lo tanto, si una ley reglamenta derechos constitucionales como son los del consumidor (conf. art 42 Constitución Nacional), y sus principios son de orden público (conf. artículo 65), no puede haber dudas sobre su paternidad frente a leyes ordinarias que regulan cuestiones comerciales sin más implicancias constitucionales que las comunes a toda la legalidad, ${ }^{28}$

\footnotetext{
Conforme lo señalaron los fundamentos del proyecto de reforma.

28 Véase Fernando Shina, "El caso Buffoni. La resucitación de la autonomía de la voluntad. La regresión de la Corte Suprema. Del milagro bíblico al anacronismo jurídico”, El Dial.com. Cita: elDial DC1D77.
} 
prevaleciendo el interés social tenido en cuenta para darle ese carácter. Esa es la interpretación social humanista que inspiró al estatuto especial del consumidor y que ahora el Código acompaña.

\section{Para interpretación de sistemas de control de precios}

Que no podían caber dudas respecto de la aplicación al caso de la Ley 24240 de Defensa del Consumidor, en la medida en que se trata de una ley de orden público que rige en todo el territorio nacional (confrontar artículo 65 de la norma). Esto era así, ya que el Convenio suscripto entre la Secretaría de Comercio y la firma imputada, aprobado por la Resolución 2/2014 de aquel organismo, establece derechos y obligaciones recíprocos y genera una oferta de productos que ha sido difundida a los consumidores en general. Es sobre dicha oferta que se proyectan los deberes de los proveedores para con los consumidores, previstos en las disposiciones de la citada ley. Cualquier otra interpretación llevaría al absurdo jurídico de entender que el Convenio suscripto operaría como derogación singular de una ley de orden público sancionada por el Poder Legislativo. ${ }^{29}$

\section{E. Para la recomposición de un contrato en supuestos de crisis económicas}

Es constitucionalmente admisible recomponer, en el contexto de la emergencia - leyes 25798 y 26167 - , un mutuo hipotecario a favor de la parte débil, pues, la protección de los consumidores, la vinculación del contrato con derechos fundamentales de la persona, la tutela de la vivienda familiar, la frustración del fin del contrato o la evidencia del abuso del derecho son la base de un "orden público de protección de la parte débil", por lo que no se afecta la igualdad cuando el legislador elige a un grupo de sujetos para protegerlos especialmente, por su vulnerabilidad. (Del voto del doctor Lorenzetti.) $)^{30}$

\section{Temas procesales}

\section{A. Intervención del Ministerio Público}

La intervención del Ministerio Público está ordenada en defensa y garantía de la ley y el orden público, razón por la cual no puede considerarse subsanada por el consentimiento del consumidor. Haber omitido en la Alzada dar intervención al Sr. Fiscal de Cámara previo al dictado de la resolución bajo anatema que resuelve el recurso de apelación plantado, determina la nulidad del procedimiento recurrido. ${ }^{31}$

29 Cámara Nacional de Apelaciones en lo Contencioso Administrativo Federal Sala II, 06/11/2014, "INC S.A. c/ DNCI s/ Recurso Directo de Organismo Externo", El dial.com. Cita: elDial AA8BF8.

30 Corte Suprema de Justicia de la Nación, 06/05/2008, “Fecred S.A. c. Mazzei, Osvaldo Daniel y otro", Diario La Ley, 20 de mayo de 2008.

31 Tribunal Superior de la Provincia de Córdoba, "Jiménez Tomas c. Citibank S.A. y otra. Ordinario. Recurso Directo. Sentencia del 2/7/2003”, La Ley Córdoba (2003): 1223. 


\section{B. En acuerdos transaccionales de acciones colectivas}

En una acción en la cual se declaró, por violación de normas consumeriles de orden público, la nulidad de un acuerdo transaccional celebrado entre una Asociación de Consumidores y una entidad financiera, debe otorgarse legitimación activa, en sustitución de aquella, al Ministerio Público Fiscal, pues los vicios que exhibe el acuerdo demuestran, por lo menos, una falta ostensible de contracción en el cuidado de los intereses de aquellos a quienes adujo representar. ${ }^{32}$

\section{Para la verificación del fumus bonus juris en las medidas cautelares}

Sostiene Gordillo que la verosimilitud del derecho "cuando se trata de usuarios y consumidores, tiene una presunción legal, iuris et de iure, otorgada a su favor por una ley federal de orden público, la 2.240 ". ${ }^{33}$

\section{Considerar (o no) prescripta una acción}

Se ha sostenido que en materia de prescripción debe prevalecer una apreciación tendiente a mantener vivo el derecho en caso de duda (principio in dubio pro consumidor), y buscar favorecer a los usuarios en la medida que se admite el ejercicio de la acción procesal brindándole mayor tiempo del que disponían anteriormente para promover el pleito y resguardar su derecho. ${ }^{34}$

Ello así, atentos a la directa derivación de normas constitucionales que impregnan esa jerarquía a la Ley de Defensa del Consumidor, conforme el artículo 42 de la Carta Magna, a más de su contenido de orden público en términos de su artículo 65. De allí su prevalencia sobre los plazos de prescripción obrantes en el derecho común, cuando estos sean menos extensos.

\section{CONCLUSIONES}

El orden público es uno de los principios fundamentales del derecho de usuarios y consumidores.

Su existencia y vigencia dependen de los valores políticos que consagraron la defensa de estos valores con el paradigma constitucional de la igualdad de oportunidades y la protección al vulnerable mediante un sistema que llamamos régimen tuitivo consumidor.

32 Cámara Nacional de Apelaciones en lo Comercial, sala C, 24/04/2014, "ADECUA c. Banco Privado de Inversiones S.A. s/ ordinario", Diario La Ley, 17 de julio de 2014.

33 Agustín Gordillo, Tratado de Derecho Administrativo", tomo III, cap. XIII, "La Defensa del usuario y del administrado" (Buenos Aires: Fundación de Derecho Administrativo, 2010), 27.

34 Véase Atilio Alterini, "Las reformas a la Ley de Defensa del Consumidor, veinte años después", Suplemento de Reforma de La Ley de Defensa del Consumidor, La Ley (2008 B): 1239. 
La efectividad de los derechos del consumidor consiste en las siguientes notas indisponibles para las partes e irrenunciables para el consumidor: a) mínimo inderogable, por cuanto un contrato o una ley pueden reconocerlos de manera adicional, pero no ignorarlos o reducirlos; b) operatividad, por cuanto permiten en su caso al juez aplicar el principio protectorio constitucional al caso si está suficientemente especificado; c) inconstitucionalidad, en caso de norma que se le oponga en grado de implicar derogación de la protección; d) ineficacia contractual en relación a la cláusula abusiva o práctica abusiva, es decir, que restringe los derechos de los consumidores; ${ }^{35} \mathrm{y}$ e) aplicación inmediata de la norma más favorable a las relaciones en curso en el cambio de legislación, aunque sean normas supletorias.

Esa efectividad se refuerza con la convivencia del estatuto especial del consumidor argentino (Ley 24240) y la reciente sanción del Código Civil y Comercial impregnado de respeto al orden público, en tanto esa relación debe verse e interpretarse conforme el principio de norma más favorable al consumidor, como favor debilis.

Este principio fundante tiene profundas implicancias prácticas en la aplicación cotidiana de la defensa de estos derechos, tanto en aspectos de fondo como procesales o instrumentales.

\section{REFERENCIAS}

- Alterini, Atilio. "Las reformas a la Ley de Defensa del Consumidor, veinte años después". Suplemento de Reforma de La Ley de Defensa del Consumidor. La Ley (2008 B).

- Barocelli, Sergio Sebastián. "Principios y ámbito de aplicación del derecho del consumidor en el nuevo Código Civil y Comercial. Derecho Comercial, del Consumidor y de la Empresa (febrero 2015).

- Cámara Nacional de Apelaciones en lo Comercial, sala A, 17/05/2000. "Western Universal Management Inc. c Nosiglia, Enrique”. La Ley (2001-A).

- Cámara Nacional de Apelaciones en lo Civil, sala A. "Petrillo, José Luis c. Repetto, Oscar Osvaldo y otros s/daños y perjuicios", 11/04/2013. Responsabilidad Civil y Seguros, IX (2013).

- Cámara Nacional de Apelaciones en lo Contencioso Administrativo Federal, Sala II, 06/11/2014. "INC S.A. c/ DNCI s/ Recurso Directo de Organismo Externo". El dial. com. Cita: elDial AA8BF8.

35 Véase Cámara Nacional de Apelaciones en lo Comercial, sala C, 25/10/2012, "Orobe Elisa c/ Alra SA s/ Ordinario", Microjuris. Cita: MJ-JU-M 75549-AR. 
- Cámara Nacional de Apelaciones en lo Civil. “Sáez González Julia del Carmen c/ Astrada Armando Valentín y otros s/ daños y perjuicios (acc. trán. c/ les. o muerte)”, 12/3/2012. Microjuris. Cita: MJ-JU-M-70925-AR/MJJ70925/MJJ70925.

- Cámara Nacional de Apelaciones en lo Comercial. Sala B, 23-2-99. "Banco de Galicia c. L.H., P.M. y otros". La Ley (1999 E).

- Cámara Nacional de Apelaciones en lo Comercial, sala F, 19/02/2015. "Banco de Galicia y Buenos Aires S.A. c. Dayan, Gonzalo s/ ejecutivo". La Ley on line. Cita: AR/ JUR/604/2015.

- Cámara Nacional de Apelaciones en lo Comercial, Sala F. "Banco Supervielle S.A. c. Chicui Héctor”, 27/4/2010. La Ley on line. Cita: AR/JUR/22408/2010.

- Cámara Nacional de Apelaciones en lo Comercial, sala C, 24/04/2014. "ADECUA c. Banco Privado de Inversiones S.A. s/ ordinario”. Diario La Ley, 17 de julio de 2014.

- Cámara Nacional de Apelaciones en lo Comercial, sala F, 19/02/2015. "Banco de Galicia y Buenos Aires S.A. c. Dayan, Gonzalo s/ ejecutivo". La Ley on line. Cita: AR/ JUR/604/2015.

- Cámara Nacional de Apelaciones en lo Comercial, sala C, 25/10/2012. “Orobe Elisa cl Alra SA s/ Ordinario”. Microjuris. Cita: MJ-JU-M 75549-AR.

- Corte Suprema de Justicia de la Nación, 06/05/2008. "Fecred S.A. c. Mazzei, Osvaldo Daniel y otro". Diario La Ley, 20 de mayo de 2008.

- Gordillo, Agustín. Tratado de derecho administrativo". Tomo III. Cap. XIII. "La Defensa del usuario y del administrado". Buenos Aires: Fundación de Derecho Administrativo, 2010 .

- Farina, Juan M. Defensa del consumidor y del usuario. Buenos Aires: Ed. Astrea, 2008.

- Juzgado Nacional de Primera Instancia en lo Comercial Nro. 16, 30/8/2010. "Cooperativa Palamates Ltda. C. Cabral Roberto”. La Ley on line. Cita: AR/JUR/45567/2110.

- Llambías, Jorge Joaquín. Tratado de derecho civil. Parte general. Tomo I. Buenos Aires: Lexis Nexis, 2007.

- López Alfonsín, Marcelo Alberto. Protección constitucional de consumidores y usuarios. Buenos Aires: Ed. Estudio, 2000.

- Lorenzetti, Ricardo Luis. Consumidores. Buenos Aires: Ed. Rubinzal- Culzoni, 2009. 
- Luqui, Roberto Enrique. "Reflexiones sobre el concepto de orden público". La Ley on line. Cita AR/DOC/283/2016.

- Molina Sandoval, Carlos A. "Reformas sustanciales". Suplemento La Ley, "Reforma de La Ley de Defensa del Consumidor". La Ley (2008).

- Mosset Iturraspe, Jorge. "El orden público y la tutela del consumidor o usuario". Revista $U N A M, \mathrm{~N}^{\circ} 90$, año $\mathrm{V}$ (enero-diciembre 2008): 223-233.

- Puga, Mónica. "El derecho y el orden público, con particular referencia al derecho del Consumo". El Dia. Cita: elDial.com - DC189D.

- Rivera, Julio César. Instituciones de derecho civil - Parte general. Tomo I. Buenos Aires: Ed. Abeledo Perrot, 1997.

- Shina, Fernando. "El caso Buffoni. La resucitación de la autonomía de la voluntad. La regresión de la Corte Suprema. Del milagro bíblico al anacronismo jurídico”. El Dial.com. Cita: elDial DC1D77.

- Taboada, Marcelo. "En torno a La Ley de Defensa del Consumidor y a las observaciones formuladas por el Poder Ejecutivo". La Ley (1994-A): 766. Cita online: AR/ DOC/20155/2001.

- Tribunal Superior de la Provincia de Córdoba. "Jiménez Tomas c. Citibank S.A. y otra. Ordinario. Recurso Directo. Sentencia del 2/7/2003”. La Ley Córdoba (2003).

Recibido: $12 / 08 / 16$

Aceptado: 19/10/16 


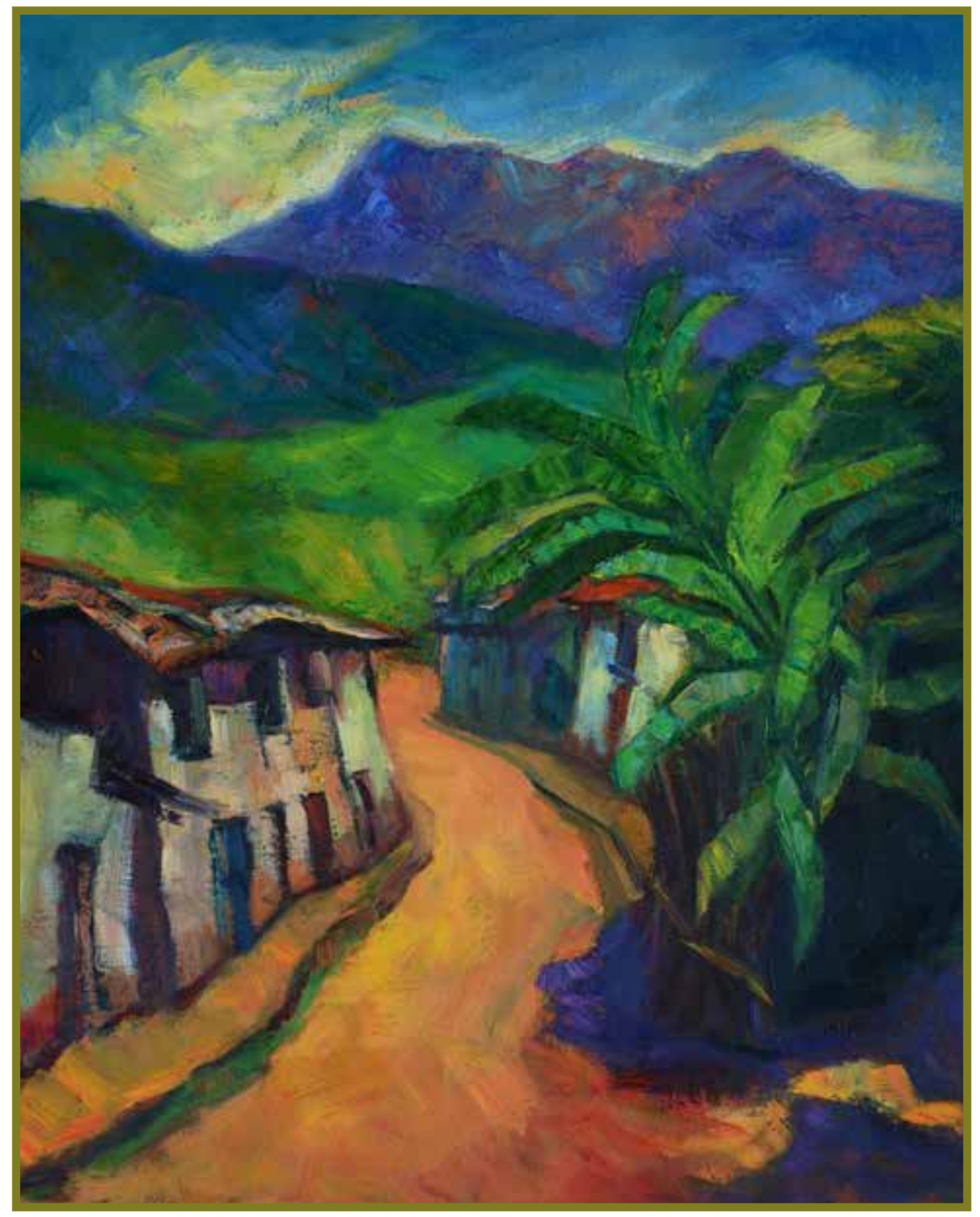

Bolivar. Óleo sobre lienzo $(54 \mathrm{~cm}$ x $73 \mathrm{~cm})$. Ever Arrascue. 